\title{
EXPERIMENTAL INVESTIGATIONS ON METHANOL FUELLED D.I DIESEL ENGINE WITH CATALYTIC COATINGS ASSISTED BY GLOW PLUG
}

\author{
Suresh. $R^{1^{*}}$, Subash Chandra Bose. $R^{2}$,Arumugam. $K^{3}$, Anbazhagan. $R^{4}$, Sathiyamoorthy. $V^{5}$ \\ ${ }_{1,4,5}$ Associate Professor, ${ }^{3}$ Professor \\ Department of Mechanical Engineering \\ Vel Tech High Tech Dr.Rangarajan Dr.Sakunthala Engineering. College, Tamilnadu, India \\ ${ }^{2}$ Principal, Sun Engineering college,Nagercoil,Tamilnadu,India. \\ * Corresponding Author E-mail: sureshr77@gmail.com
}

\section{ABSTRACT}

A comprehensive study on the methanol with three different types of Catalytic coatings assisted by Glow Plug is discussed in this paper. A four stroke single cylinder water cooled D.I diesel engine was adopted for the experiment. The present study aims to evaluate the Performance and Emission characteristics level of methanol fuel with three types of catalytic coatings assisted by Glow Plug. The catalytic coatings have established enhanced rate of combustion, which results in increased brake thermal efficiency. These methods of coating are selected based on generally available technologies and reviews of several researchers through their literature reviews. In this study, the diesel engine was tested using methanol coated with three types of catalytic coatings namely Copper, Aluminium oxide, and Chromium oxide and assisted by Glow Plug respectively. The influence of various catalytic coatings in combustion chamber(cylinder head inner surface, piston, valve) results in tremendous changes in the various parameters of the GHSI engine. The Exhaust temperature for Copper coating was higher compared to Aluminium oxide coating and Chromium oxide coating. It is noticed that, brake thermal efficiency was thus improved in almost all operation conditions with the Methanol fuels. The $\mathrm{HC}$ and $\mathrm{CO}$ emissions are higher at Methanol fuelled with Copper coating. NOx and Smoke emissions are lower for Chromium oxide coating compared to Copper coating and Aluminium oxide coating. Among all coatings, Copper coating exhibits better efficiency and lower emission compared to other coatings.

Keywords: Ceramic Coatings, DI engine, Glow plug, Hot Surface ignition Engine, Methanol.

\section{INTRODUCTION}

Alternate fuels gained attention day by day around the globe due to their added advantages over fossil fuel. Alcohol fuels, one among the alternate fuel, offer potential to mitigate national security and economic concerns over fuel supplies as well as environmental concerns over tailpipe emissions. Last several years of automotive research, a variety of alcohol fuels-primarily methanol, ethanol and blends with hydrocarbon fuels have been investigated. The results showed better emissions of oxides of nitrogen (NOx) and particulate matter (PM) as well as moderately improved brake thermal efficiency Nabi MN et al. [1], Miyamoto $\mathrm{N}$ et al.[2], Baranescu R etal.[3], Dhaliwal B et al [4]. In spite of this, notably cold starting has limited the widespread use of neat alcohol-fueled vehicles. Benefits of alcohol fuels such as higher efficiency, specific power output and lower emissions, their high octane number gives the ability to operate at higher compression ratio without problems Brinkman ND [5]; their greater latent heat of vaporization gives higher charge density and their higher laminar flame speed allows them to be run with leaner or more dilute air/fuel mixtures Ryan T et al. [7]. In addition, alcohols generally give lower fuel heat release rates, resulting in lower NOx emissions and reduced combustion noise Miyamoto $\mathrm{N}$ et al. [2]. One of the main challenges with neat alcohol fuels is cold start emissions, especially in PFI engines Battista $V$ et al. [8]. In such applications, the low vapor pressure and low Cetane number must overcome with higher-energy ignition systems or higher compression ratios Hikino $\mathrm{K}$ et al. [9].

Further, the increased wetting of the intake manifold, cylinder walls and Glow plugs must be addressed in the design of the combustion chamber and in the control of transient fueling during startup Battista $\mathrm{V}$ et al. [8], Dodge LG et al. [10]. In this paper, the experimental investigations are carried out on GHSI engine with methanol as fuel, with different catalytic coatings to the combustion chamber. The base engine with standard configuration is fitted with aluminum piston without any coating to the combustion chamber; it is utilized for the experiment. The different coatings that are used in this work are Copper coating, Aluminium oxide coating and Chromium oxide coating. Various performance parameters for above coatings to the combustion chamber and Piston on the glow plug Hot Surface Ignition (GHSI) engine are studied along with emission and combustion parameters B.Karthikeyan et al. [11], Jin Kusaka et al.[12]. Experimental work is carried out to evaluate the variousparameters like Brake thermal efficiency, Volumetric efficiency, Exhaust gas temperature, Hydro carbon emission, Carbon monoxide emission, Nitrogen oxides emission and combustion parameters J.V. Pastor et al. [13], C.G.McCreath [14]. By the usual engine testing method, we can measure these parameters. Then, by analyzing the results, we can identify the best catalytic coating which provides higher engine efficiency, low emissions and good combustion rate when using methanol as a fuel [16], M. Cerit et al [17]. The influence of various catalytic coatings in combustion chamber and Piston results in tremendous changes in the various parameters of the engine R.P.Glovnea et al. [18]. The results are clearly discussed below.

\section{EXPERIMENTAL SET UP}

A single cylinder water-cooled D.I Diesel engine developing a power output of $4.4 \mathrm{~kW}$ at the rated speed of 1500 $\mathrm{rpm}$ is used for the experimental studies. The specification of the engine is given in Table 1 and the comparison of fuel properties is shown in Table 2.The schematic of Experimental setup and Photographic view are shown in Fig. 1 and Fig.2.

$6341 \mid \mathrm{P}$ a g e 
The Glow plug is mounted on the engine at the top of the cylinder head, after selecting an optimized location. The Glow Plug is connected to the engine cylinder head and it is connected to a battery via ignition coil. The coating is given to the engine Combustion chamber (cylinder head), Valve and Piston crown by means of Plasma spray painting up to a thickness of 150 micron meter $(0.15 \mathrm{~mm})$. The engine is coupled to an electrical Eddy current dynamometer. The engine is started with neat diesel fuel and warmed up. It is allowed to run for 10 minutes with diesel to attain steady condition at its rated speed. The governor of the engine is used to maintain a constant speed of $1500 \mathrm{rpm}$. The combustion chamber is hemispherical in shape. The engine is gradually loaded to full-load by switching on the load mains. The injector opening pressure recommended by the manufacturer is 200 bar. The exhaust of the engine is collected and sent out by a central facility, which maintained a constant pressure close to ambient in the exhaust manifold. The time taken for 10cc of fuel consumption is measured using a stopwatch. The tests are conducted for various loads for five times and the average values of the five readings are taken to eliminate the uncertainty.

The in-cylinder pressure, NOX, CO, HC, Smoke, and Exhaust gas temperature are measured at different loads with different test fuels. A Kistler Piezoelectric transducer with a range of 0 to $250 \mathrm{bar}$ is used to measure the cylinder pressure. The Piezoelectric transducer is mounted on the cylinder head and connected to a Charge amplifier for measuring the pressure inside engine cylinder. AVL's Software Indimeter 619 version 2.2 is used to measure the heat release rate, inside cylinder pressure, Mean effective pressure etc. A TDC (Top Dead Centre) AVL 364 optical encoder is used to detect the engine crank angle. NOX, CO, and HC emissions are measured by AVL Digas-444 exhaust gas analyzer. Smoke intensity is measured using a Bosch smoke meter. The temperature of the exhaust gas is measured with Chromel Alumel (K-Type) thermocouples. At each load, the required parameters are measured and analyzed for five times and the average is taken to eliminate the uncertainty.

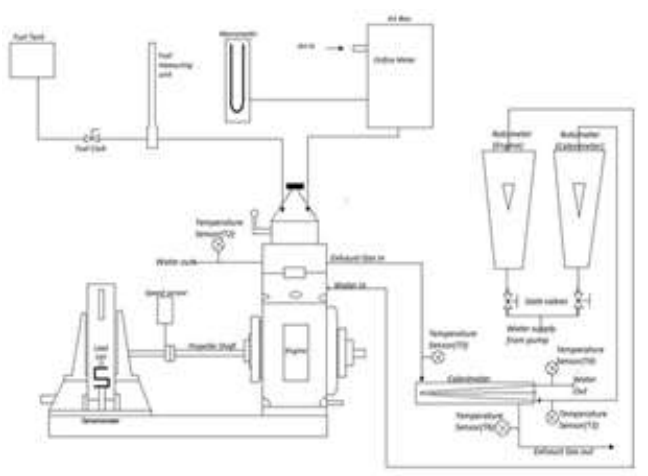

Fig.1.Schematic showing experimental set up

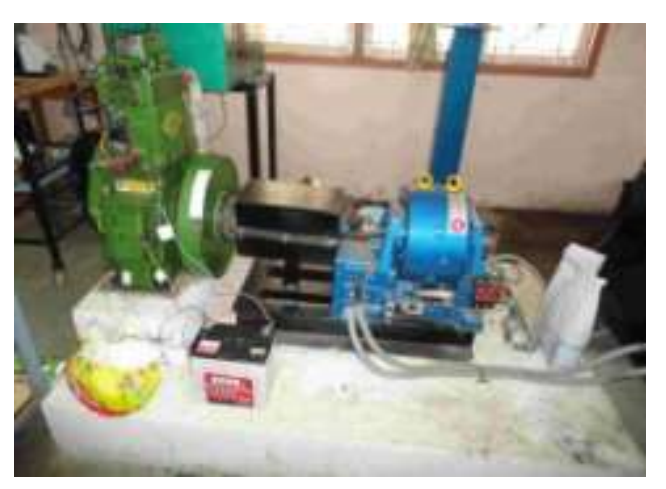

Fig.2. Photographic View of experimental set up

Table 1. Engine Specifications

\begin{tabular}{|l|l|}
\hline Make & Kirloskar TAF-1 \\
\hline Cylinder & One \\
\hline Cycle & Four-Stroke \\
\hline Injection & Direct Injection \\
\hline Aspiration & Naturally Aspirated \\
\hline Cooling & Water cooled \\
\hline Bore & $85.5 \mathrm{~mm}$ \\
\hline Stroke & $110 \mathrm{~mm}$ \\
\hline Compression Ratio & $17.5: 1$ \\
\hline Power Output & $4.4 \mathrm{~kW}$ at 1500rpm \\
\hline Injection Pressure & 200 bar \\
\hline Static Injection Timing & $23^{0}$ Before TDC \\
\hline
\end{tabular}

Table 2. Comparison of fuel properties

\begin{tabular}{|l|c|c|c|c|}
\hline \multicolumn{1}{|c|}{ Properties } & Methanol & Ethanol & Petrol & Diesel \\
\hline Chemical formula & $\mathrm{CH}_{3} \mathrm{OH}$ & $\mathrm{C}_{2} \mathrm{H}_{5} \mathrm{OH}$ & - & - \\
\hline Molecular weight & 32 & 46 & - & - \\
\hline Boiling point $\left({ }^{\circ} \mathrm{C}\right)$ & 64.5 & 78 & $40-190$ & $170-340$ \\
\hline
\end{tabular}




\begin{tabular}{|l|c|c|c|c|}
\hline Density at $20^{\circ} \mathrm{C}\left(\mathrm{kg} / \mathrm{m}^{3}\right)$ & 0.792 & 0.789 & 0.74 & 0.84 \\
\hline Stoic. air/Fuel ratio & $6.4: 1$ & $9: 01$ & $14.7: 1$ & - \\
\hline Cetane No. & 3 & 8 & 10 & $50-55$ \\
\hline Octane No. & 92 & 90 & $80-90$ & - \\
\hline Calorific value $(\mathrm{kJ} / \mathrm{kg})$ & 23800 & - & 43600 & 44500 \\
\hline Flash point $\left({ }^{\circ} \mathrm{C}\right)$ & 11 & - & 43 & 52 \\
\hline Auto ignition temp $\left({ }^{\circ} \mathrm{C}\right)$ & 464 & 360 & $220-260$ & $180-240$ \\
\hline
\end{tabular}

\section{RESULTS AND DISCUSSION}

\subsection{Performance Parameters}

\subsubsection{Brake Thermal Efficiency}

The brake thermal efficiency with brake power for three different coatings coated on the combustion chamber with GHSI engine is explained diagrammatically in Fig.3. It is found that, the brake thermal efficiency for all catalytic coatings to GHSI engine are higher as compared to plain GHSI engine with methanol as fuel over wide range of operation. The GHSI engine with Copper coating shows maximum efficiency over various operations carried. The GHSI engine with plain combustion chamber indicates minimum efficiency when compared over other coating considering wide range of operation.

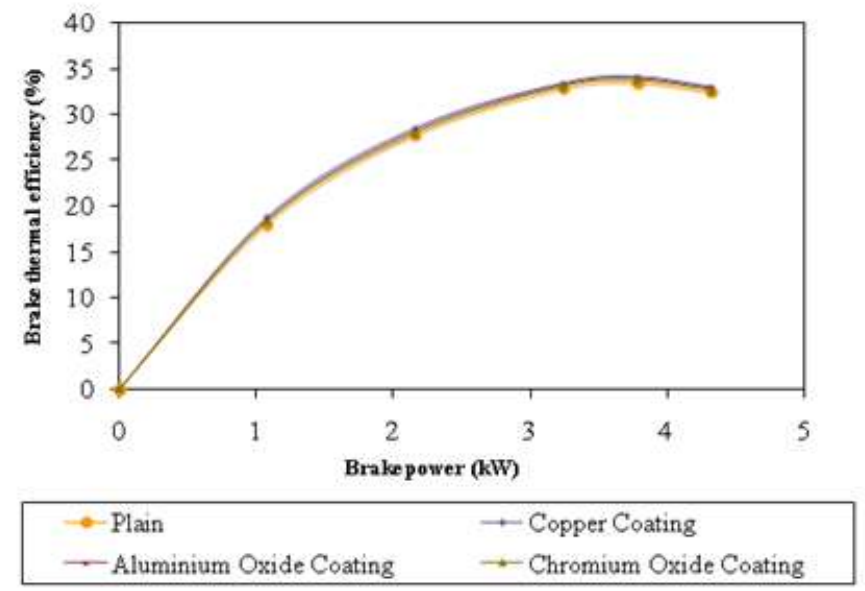

Fig. 3.Variation of Brake thermal efficiency with Brake power for different coatings

The brake thermal efficiency of plain GHSI engine, Copper coating, Aluminium oxide coating, and Chromium oxide coating at maximum load are $32.47 \%, 32.60 \%, 32.57 \%, 32.54 \%$ respectively. It can be obtained by the formulae

$$
\eta_{\text {втн }}=\frac{(\text { Brake Power } \times 3600)}{(\text { TFC } \times \text { Heating value })} \times 100
$$

The brake power can be obtained by the formulae

$$
\text { Brake power }=\frac{(V \times I)}{\left(\eta_{G} \times 1000\right)}
$$

The GHSI engine with plain combustion chamber indicates minimum efficiency as compared to other coatings placed over the GHSI engines. This is due to the positive ignition of injected methanol sprayed under all conditions by Copper coated GHSI engine.

\subsubsection{Volumetric Efficiency}

The difference in volumetric efficiency with brake power output between the three types of catalytic coatings along with the GHSI engine is visualized in the Fig.4. 


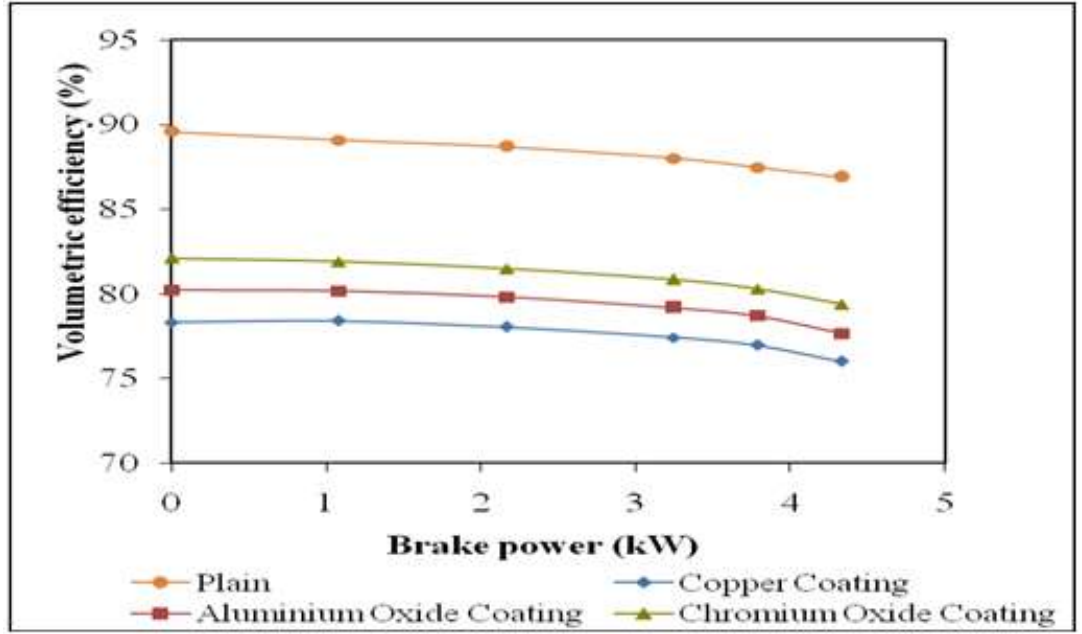

Fig. 4. Variation of Volumetric efficiency with Brake power for different coatings

The volumetric efficiency of plain GHSI engine, Copper coating, Aluminium oxide, and Chromium oxide at maximum load is $86.88 \%, 75.57 \%, 77.29 \%, 79.01 \%$ respectively. It can be obtained by the formulae

$$
\eta_{\mathrm{v}}=\frac{\text { Mass of ch } \arg \text { e actually sucked in }}{\text { Mass of charg e corresponding to the cylinder int ake } P \text { and } T \text { conditions }}
$$

It is observed that, drop in volumetric efficiency is more for Copper coatings in GHSI engine. The drop in volumetric efficiency for the other coatings varies depending upon the degree of insulation which they are coated. The combustion chamber surface temperature is very high during the suction stroke, the heat transfer to the incoming air is high which tends to decrease the volumetric efficiency. The drop in volumetric efficiency affects combustion by reducing the amount of air available for combustion.

\subsubsection{Exhaust Gas Temperature}

The variation of exhaust gas temperature with brake power for different catalytic coatings on GHSI engine is illustrated in Fig.5.

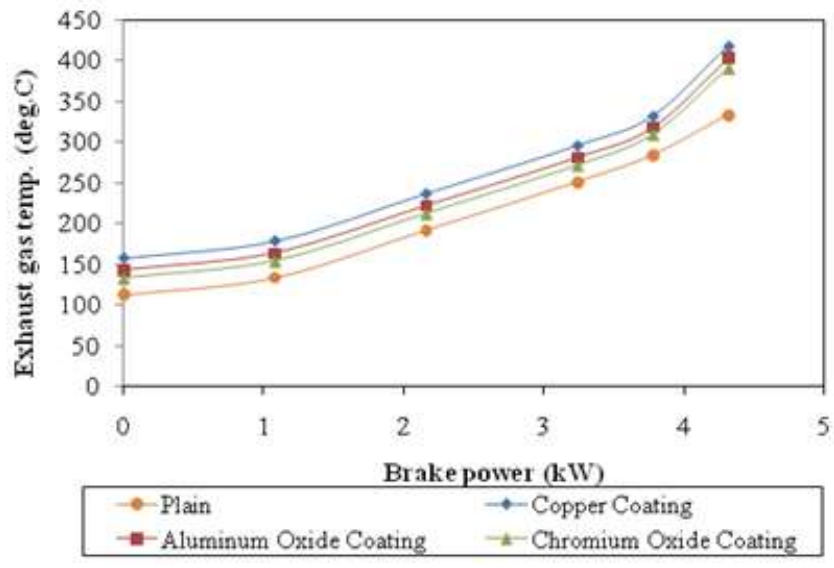

Fig.5. Variation of Exhaust gas temperature with Brake power for different coatings

By using catalytic coating in combustion chamber, the exhaust temperature increases. The plain GHSI engine exhibits lower exhaust temperature among all the fuel tested i.e. $333^{\circ} \mathrm{C}$, when compared with other coatings at rated load condition. The exhaust temperature for Copper coating, Aluminium oxide, and Chromium oxide at maximum load is $418^{\circ} \mathrm{C}, 403^{\circ} \mathrm{C}$, and $393^{\circ} \mathrm{C}$ respectively.

\subsection{Emission Parameters}

\subsubsection{Hydro Carbon emissions}

The variation in hydrocarbon (HC) emission levels with power output is represented in Fig.6. The Copper coated GHSI engine shows lowest $\mathrm{HC}$ emissions. The reduction in $\mathrm{HC}$ emissions level for Copper coated $\mathrm{GHSI}$ engine over the other coatings is about 5 PPM at maximum load. The hydrocarbon emission for Copper, Aluminium 
oxide, and Chromium oxide at maximum load is 150 PPM, 152 PPM, and 155 PPM respectively. The HC emission level for the other entire coated GHSI engine is higher at lower loads. This is because the location of the ignition source with respect to fuel injector is optimized for the rated load operation. In case of GHSI engine, it is also noticed that the $\mathrm{HC}$ emissions are higher at low loads higher than rated load. The $\mathrm{HC}$ emission level for all the other coated GHSI engine are in between the plain GHSI engine and the Copper coated GHSI engine with methanol as fuel.

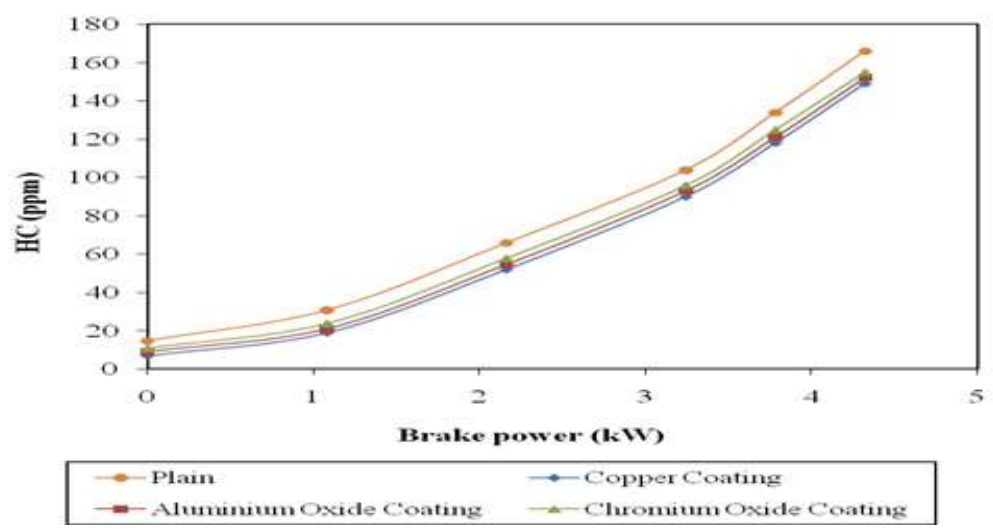

Fig.6. Variation of hydrocarbon emission with brake power for different catalytic coatings

\subsubsection{Carbon Monoxide emissions}

The Fig.7 illustrates the variation of Carbon monoxide with power output. The Copper coating GHSI engine indicates lower level of Carbon monoxide emissions when compared to that of other two coatings on GHSI engine. In GHSI engine, the variation of Carbon monoxide emission at lower output is negligible.

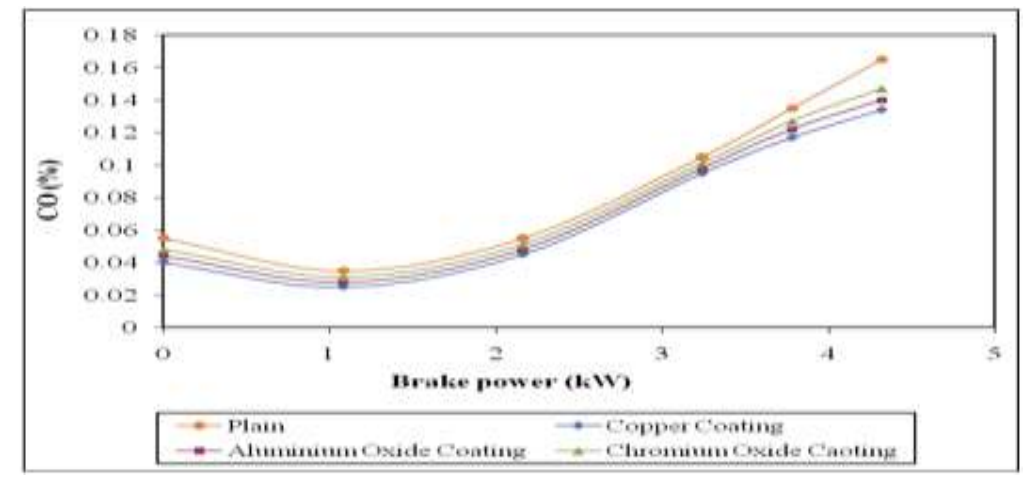

Fig.7. Variation of $\mathrm{CO}$ emission with brake power for different catalytic coatings

The Carbon monoxide emission for Copper coating, Aluminium oxide, and Chromium oxide at maximum load are $0.125 \%, 0.135 \%$, and $0.141 \%$ respectively. The reduction for Copper coating is about $0.005 \%$ when compared to Aluminium oxide and Chromium oxide coating at maximum load.

\subsubsection{Nitrogen Oxide emission}

This Fig.8 shows the Nitrogen oxide levels for various coatings of a GHSI engine. Complete combustion takes place, due to higher combustion chamber temperature in the catalytic coated GHSI engine and the oxidation rate of nitrogen oxide is also improved.

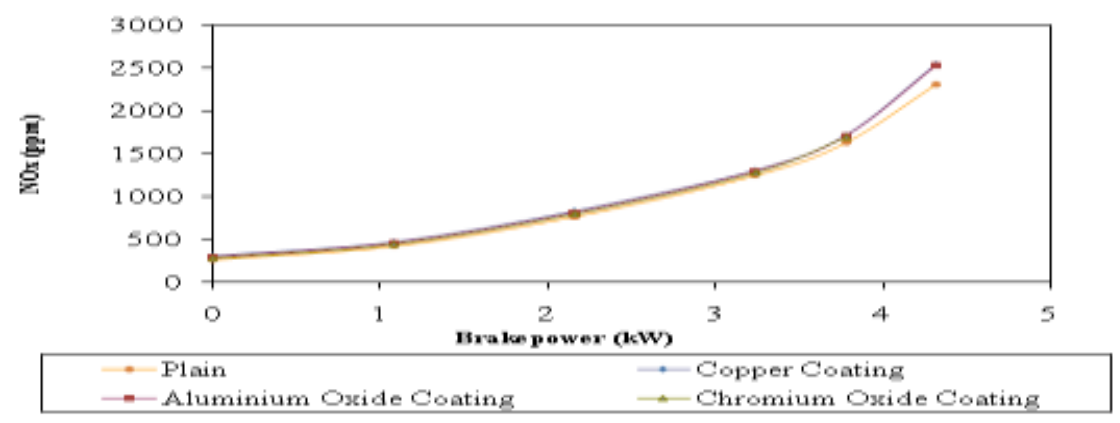

Fig.8. Variation of nitrogen oxide with brake power for different catalytic coatings 
The GHSI engine with Chromium oxide coating gives the lowest nitrogen oxide emission and is about 10 to 20 PPM with that of other coatings at rated load. The Nitrogen oxide emission for Copper coating, Aluminium oxide and Chromium oxide coating at maximum load is $2545 \mathrm{ppm}, 2535 \mathrm{ppm}, 2525 \mathrm{ppm}$ respectively. Out of all the coatings which are experimented, nitrogen oxide emission is higher with copper coated GHSI engine when compared to that of the other coatings on the GHSI engine.

\subsubsection{Exhaust Smoke emissions}

The study of exhaust emission for different coated GHSI engine is shown in Fig.9. The Copper coated GHSI engine gives the lowest Smoke emission almost over the entire operating range. The Exhaust smoke emission of Copper coating, Aluminium oxide, and Chromium oxide at maximum load are 1.504 BSU, 1.754 BSU and 2.005 BSU respectively.

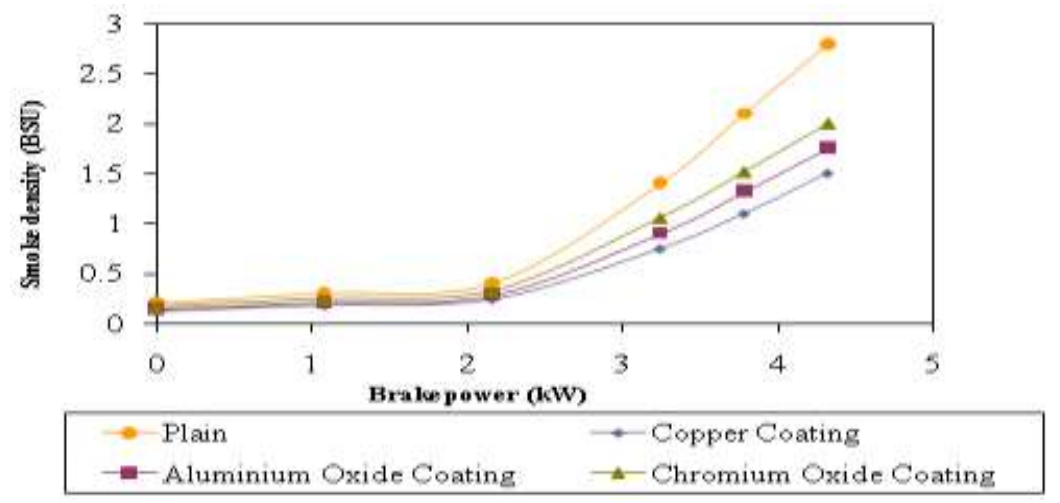

Fig.9. Variation of exhaust smoke emission with brake power for different catalytic coatings

Aluminium oxide and chromium oxide coatings can be taken into account in the reduction of smoke emission. At maximum load, the maximum reduction in smoke emission is noted to be $1.504 \mathrm{BSU}$ for copper coated GHSI engine and the reduction is about $0.501 \mathrm{BSU}$ to $0.25 \mathrm{BSU}$.

\section{CONCLUSION}

Out of three coatings coated on the combustion chamber of the GHSI engine, hopefully the Copper coating on the GHSI engine is proved to be good in terms of performance and emission as compared to plain GHSI engine.

- The brake thermal efficiency for the Copper coated GHSI engine is $32.6 \%$ and it is quite high than the plain GHSI engine which is $32.47 \%$ at maximum load. This is due to positive ignition of the injected methanol spray under all conditions.

- The volumetric efficiency is $86.88 \%$ for plain GHSI engine which is the highest and $75.57 \%$ for Copper coating which is the minimum when compared to other coatings.

- The exhaust gas temperature for plain GHSI engine is $333^{\circ} \mathrm{C}$ and is the lowest when compared to other coatings, Copper coating shows higher exhaust gas temperature of $418^{\circ} \mathrm{C}$.

- It is found that the minimum smoke emission is noted as 1.504 BSU for Copper coated GHSI engine when compared to other coatings, and plain GHSI engine shows higher smoke emission of 2.806 BSU.

- The Copper coated GHSI engine shows the lowest HC emission of 150 ppm, where plain GHSI engine shows the highest $\mathrm{HC}$ emission of $160 \mathrm{ppm}$.

- The Copper coated GHSI engine gives the lowest level of CO emissions of $0.125 \%$ and plain GHSI engine gives the highest level of CO emission of $0.165 \%$.

- The plain GHSI engine gives the lowest $\mathrm{NO}_{x}$ emission of 2300 ppm ,where as the Copper coating gives the maximum NOx emission of $2545 \mathrm{ppm}$.

\section{REFERENCES}

[1] Nabi MN et al. (2000) Ultra Low emission and high performance diesel combustion with highly oxygenated fuel. SAE Paper 2000-01-0231.

[2] Miyamoto $\mathrm{N}$ et al. (1998) Smokeless, low nox, high thermal efficiency, and low noise diesel combustion with oxygenated agents as main fuel. SAE Paper 980506.

[3] Baranescu $R$ et al. (1989) Prototype development of a methanol engine for heavy- duty application- performance and emissions. SAE Paper 891653.

[4] Dhaliwal B et al. (2000) Emissions effects of alternative fuels in light-duty and heavy-duty vehicles", SAE Paper 
[5] Brinkman ND (1977) Effect of compression ratio on exhaust emissions and performance of a methanol fueled single-cylinder engine. SAE Paper 770791.

[6] Mohanan P, Babu GMK (1991) A Simulation model for a methanol-fueled turbocharged multi- cylinder automotive spark ignition engine. SAE Paper 912417.

[7] Ryan T, Lestz S (1980) The Laminar burning velocity of isooctane, n-heptane, methanol, methane and propane at elevated temperatures and pressures in the presence of a diluent. SAE Paper 800103.

[8] Battista V et al. (1990) Review of the cold starting performance of methanol and high methanol blends in spark ignition engines: neat methanol. SAE Paper 902154.

[9] Hikino K, Suzuki T (1989) Development of methanol engine with autoignition for low nox emission and better fuel economy. SAE Paper 891842.

[10] Dodge LG et al. (1998) Development of an ethanol-fueled ultra-low emissions vehicle. SAE Paper 981358.

[11] B. Karthikeyan, K. Srithar, Performance characteristics of a glowplug assisted low heat rejection diesel engine using ethanol, Applied Energy, Volume 88,Issue 1, January 2011, Pages 323-329.

[12] Jin Kusaka, Yasuhiro Daisho, Ryoji Kihara, Takeshi Saito, Combustion and ignition characteristics in a glow plug assisted methanol DI engine (optimization of slit geometries and glow plug temperature), JSAE Review, Volume 18, Issue 1, January 1997, Pages 64-66

[13] J.V. Pastor, V. Bermúdez, J.M. García-Oliver, J.G. Ramírez-Hernández , Influence of spray-glow plug configuration on cold start combustion for high-speed direct injection diesel engines, Energy, Volume 36, Issue 9, September 2011, Pages 5486-5496.

[14] C.G.McCreath, The effect of fuel on the exhaust emissions from diesel of sprayglowplug configuration.engines, Combustion and Flame, Volume 17, Issue 3, December 1971, Pages 359-366.

[15] Muhammet Cerit , Thermo mechanical analysis of a partially ceramic coated piston used in an SI engine, Surface and coatings Technology, Volume 205, Issue 11, 25 February 2011, Pages 3499-3505.

[16] Tadeusz Hejwowski, Comparative study of thermal barrier coatings for internal combustion engine,Vacuum, Volume 85, Issue 5, 9 November 2010, Pages 610-616.

[17] M. Cerit, V. Ayhan, A. Parlak, H. Yasar, Thermal analysis of a partially ceramic coated piston: Effect on cold start $\mathrm{HC}$ emission in a spark ignition engine, Applied Thermal Engineering, Volume 31, Issues 2-3, February 2011, Pages 336-341.

[18] R.P. Glovnea, A.V. Olver, H.A. Spikes, Effectiveness of boundary lubricant additives on some coated surfaces, Tribology and Interface Engineering Series, Volume 48, 2005, Pages 135-143.

\section{BIOGRAPHY}

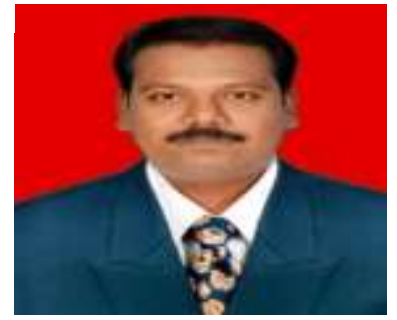

Dr.Suresh.R was born to Dr.P. Rajendran and Mrs. T. Rugmoni on 29 May 1977 in Vaithianathapuram, Kottar (P.O), Nagercoil- 629002, Kanniyakumari District, Tamil Nadu, India. He completed his Bachelor Degree in Mechanical Engineering at MEPCO Schlenk Engineering College, Sivakasi under Madurai Kamaraj University in the year 2000. He joined in Madurai Kamaraj University to do his Post Graduate Studies in Master of Business Administration and was awarded with the degree in the year 2003. He joined in Annamalai University, Chidambaram to do his Post Graduate studies in Thermal Power Engineering and was awarded the degree in the year 2005. He joined in Sathyabama University, Chennai to do his Ph.D research in I.C Engines and was awarded the degree in the year 2013.

After his post-graduation, he worked at Udaya School of Engineering from June-2005 to April-2013, Cape Institute of Technology from May-2013 to June-2015, GRT Institute of Engineering and Technology from July-2015 to August-2016 and now presently at Vel Tech High Tech Dr.Rangarajan Dr.Sakunthala Engineering College from August-2016 to Till Date. He has guided several projects in under graduate level and also in post graduate level. He has published number of scientific research papers of which Seven papers have been published in International Journals and three in International Conference proceedings and out of which one paper have been published in IEEE Explore. He has also published three papers in National Journals and four papers in National conference proceedings.

He had submitted three research proposals in SERB out of which two as Principal Co-ordinator and one as Co Principal Co-ordinator. Also, three patents have been filed out of which one as Principal Co-ordinator and two as Co Principal Co-ordinator.

$\mathrm{He}$ is been a reviewer for four International Journals, made research tie-up with lot of organizations, having membership in professional bodies, organized lot of Seminars and Conferences etc. His research areas include Internal Combustion Engines, Thermal Engineering, Fuel Chemistry, Alternative Fuels, Energy Engineering. 